Bul. Agrohorti 4(2): 241-249 (2016)

\title{
Manajemen Pemanenan Tanaman Kelapa Sawit (Elaeis guineensis Jacq.) di Kebun Serawak Damai
}

\author{
Harvest Management of Palm Oil (Elaeis guineensis Jacq.) in Serawak Damai Estate
}

\author{
Anggita Perdana, Adolf Pieter Lontoh, dan Heni Purnamawati
}

Departemen Agronomi dan Hortikultura, Fakultas Pertanian, Institut Pertanian Bogor (Bogor Agricultural University), Jl. Meranti, Kampus IPB Dramaga, Bogor 16680, Indonesia

Telp.\&Faks.62-251-8629353 e-mail agronipb@indo.net.id

*Penulis korespondensi: alfpiton@yahoo.com

Disetujui 4 Mei 2016/ Published online 9 Mei 2016

\begin{abstract}
This internship activity was conducted at Serawak Damai Estate (SDME) from March to June 2014. The internship was aimed to improve the field technical capabilities, managerial capacity in oil palm plantations and the ability to understand the field of oil palm culture production especially in harvesting process. Harvesting activity include cutting the fruit in the production field until deliver the whole fruit to the factory for processing. The quality of fruit crops, harvesting quality, transportation systems and the fruit harvesting ability of employees in third division of SDME have been observed with data sample. Output production and productivity of palm oil yield data analyzed with $t$ - student, while the fruit transportation and harvesting ability of employees were analyzed descriptively. Monthly production of third division SDME has high achievement average was $128 \%$ of the production budget. Harvesting ability of employees average were $2.8 \mathrm{ha} \mathrm{HK^{l }}$. Delayed fruit transportation usually result of the time variations was required each unit to loaded the fruit and queued at the factory was not consistent.
\end{abstract}

Keywords: fruit transportation, harvest, production, productivity

\begin{abstract}
ABSTRAK
Magang ini dilaksanakan di Kebun Serawak Damai (SDME) dari Maret sampai Juni 2014. Kegiatan magang ini bertujuan meningkatkan kemampuan teknis lapangan, meningkatkan kemampuan manajerial di perkebunan kelapa sawit, serta meningkatkan kemampuan dalam memahami budidaya lapangan produksi secara nyata terutama dalam pemanenan hasil. Kegiatan pemanenan meliputi pemotongan buah di lapangan produksi hingga pengiriman seluruh buah ke pabrik untuk diproses. Kualitas buah hasil panen, mutu hancak, sistem transportasi buah dan kemampuan panen karyawan harian pada Divisi tiga SDME diamati dengan pengambilan contoh data. Data hasil produksi dan produktivitas panen kelapa sawit dianalisis dengan uji $t$ - student, sedangkan transportasi buah dan kemampuan panen karyawan harian dianalisis secara deskriptif. Divisi tiga SDME memiliki produksi bulanan yang tinggi dengan pencapaian rata - rata $128 \%$ terhadap budget produksi. Kemampuan panen rata - rata tenaga kerja sebesar 2.8 ha $\mathrm{HK}^{-1}$. Transportasi buah sering mengalami keterlambat akibat variasi waktu yang dibutuhkan unit untuk memuat buah dan antri di pabrik tidak konsisten.
\end{abstract}

Kata kunci : panen, produksi, produktivitas, transportasi buah 


\section{PENDAHULUAN}

Semakin ketat persaingan sektor agribisnis dalam mengembangkan pembangunan jangka panjang secara terpadu. Meningkatkan pula penerapan intensitas kegiatan teknis dan manajemen. Keadaan tersebut juga dialami oleh agribisnis kelapa sawit. Komoditas Kelapa Sawit yang muncul sebagai primadona dalam dunia pertanian beberapa tahun terakhir. Menurut Lubis (1992) Tanaman kelapa sawit (Elaeis guineensis Jacq.) adalah tanaman penghasil minyak nabati berkualitas tinggi, karena minyak yang dihasilkan memiliki berbagai keunggulan dibandingkan minyak yang dihasilkan dari tanaman lain. Produk tanaman kelapa sawit adalah produk multi fungsi, antara lain untuk pembuatan minyak margarin, minyak goreng, bahan baku tekstil dan juga sebagai bahan kosmetik. Kebutuhan tanaman kelapa sawit dalam sistem yang dikembangkan FAO yaitu daerah tropis dengan temperatur harian selama 24 jam $>20{ }^{\circ} \mathrm{C}$ dan periode pertumbuhan $\geq 270$ hari per tahun. Malaysia dan Indonesia merupakan dua negara utama penghasil minyak sawit yang menguasai sekitar $85 \%$ pangsa pasar dunia (Pahan, 2010). Komoditas ini telah berhasil mengatasi kekurangan minyak goreng yang berasal dari kelapa sejak tahun 1972.

Pemahaman atas potensi komoditas tersebut, menjadi dasar diusahakan perkebunan kelapa sawit secara intensif untuk mencapai produktivitas optimum. Salah satu faktor penentu produktivitas tersebut adalah panen. Panen merupakan titik awal dari produksi dan terkait erat dengan kegiatan budidaya (Setyamidjaja, 2006). Kegiatan pemanenan menjadi penting untuk diperhatikan agar dapat meminimalkan losses (kehilangan hasil) akibat panen tidak tepat waktu dan tandan buah segar (TBS) tertinggal di lapangan. Proses pemanenan pada tanaman kelapa sawit meliputi pekerjaan pemotongan TBS, pemungutan brondolan, dan pengangkutan dari pohon ke tempat pengumpulan hasil (TPH) serta ke pabrik. Pelaksanaan pemanenan perlu memperhatikan beberapa kriteria tertentu karena tujuan panen kelapa sawit adalah untuk mendapatkan rendemen minyak yang tinggi dengan kualitas minyak yang baik. Kriteria panen yang perlu diperhatikan antara lain matang panen, cara panen, alat panen, rotasi panen dan sistem panen, serta mutu panen (Fauzi et al., 2012).

Bila pemanenan TBS dilakukan pada saat kondisi buah over ripe (lewat matang) maka akan menghasilkan minyak sawit yang mengandung asam lemak bebas (ALB) yang tinggi, namun jika pemanenan TBS dilakukan pada saat buah belum matang akan dihasilkan sedikit rendemen minyak sawit sehingga dapat menurunkan produksi perusahaan. Kegiatan pemeliharaan yang telah dilakukan sesuai dengan kebutuhan dan potensi produksi tanaman kelapa sawit, tidak ada manfaatnya apabila pemanenan tidak dilaksanakan secara optimal (PPKS, 2007)..

Kegiatan magang ini mempunyai tujuan umum meningkatkan kemampuan teknis lapangan, meningkatkan kemampuan manajerial di perkebunan kelapa sawit, serta meningkatkan kemampuan dalam memahami proses budidaya lapangan produksi secara nyata. Tujuan khusus kegiatan magang ini adalah meningkatkan pengalaman, pemahaman dan keterampilan tentang budidaya tanaman kelapa sawit terutama proses pemanenan yang terdiri dari kegiatan persiapan panen, kriteria matang panen, sistem dan rotasi panen, basis dan premi panen, alat dan perlengkapan panen serta transportasi buah.

\section{METODE MAGANG}

Kegiatan magang ini dilaksanakan di kebun Serawak Damai (SDME), Kabupaten Kotawaringin Timur, Kalimatan Tengah. Pelaksanaan magang berlangsung selama 4 bulan, dimulai pada tanggal 1 Maret sampai 30 Juni 2014.

Selama satu bulan pertama ditempatkan sebagai karyawan harian lepas (KHL). Pekerjaan yang dilakukan meliputi pengendalian gulma dan hama penyakit tanaman (HPT), pemupukan, penunasan, dan pemanenan. Bulan kedua penulis ditempatkan sebagai pendamping mandor. Tugasnya adalah mengawasi pekerjaan beberapa KHL agar berjalan sesuai instruksi perusahaan. Dua bulan terakhir pada kegiatan magang penulis ditempatkan sebagai pendamping asisten. Kegiatannya yaitu mengkoordinasikan beberapa mandor utama, membuat perencanaan operasional tahunan, dan sebagai pengambil keputusan ditingkat kebun. Selain bekerja langsung layaknya karyawan perusahaan, penulis juga melakukan pengambilan data sebagai bahan analisis terhadap aspek khusus yang diamati. Data yang diperoleh berupa data primer dan data sekunder. Data primer diperoleh melalui pengamatan atau wawancara secara langsung di lapangan, sedangkan data sekunder bisa diperoleh dari arsip perusahaan. 
Data primer yang diamati sesuai aspek khusus magang yaitu pemanenan kelapa sawit. Kegiatan yang diamati meliputi:

1. Angka kerapatan panen

Dilakukan pada blok yang akan dipanen pada seksi panen esok hari. Jumlah pokok contoh yang diamati pada pengamatan adalah 300 pokok dari setiap blok. Angka kerapatan panen dapat diketahui dengan menggunkan rumus:

$$
\mathrm{AKP}=\frac{\text { Jumlah buah matang }}{\text { Jumlah pokok yang diamati }} \times 100 \%
$$

2. Taksasi produksi

Dilakukan dengan menggunakan kemungkinan AKP hasil pengamatan, kemudian dilakukan penghitungan taksasi produksi setiap blok pada seksi tersebut.

3. Tenaga kerja panen

Kegiatan pengamatan kemampuan tenaga kerja panen dilakukan dengan menentukan 2 orang KHL pada setiap kemandoran panen sebagai objek pengamatan yang dipilih secara acak.

4. Kriteria matang panen

Kriteria matang panen diamati dari 140 TBS hasil panen 9 orang KHL yang ditentukan secara acak. Pengecekan persentasi jumlah TBS berdasarkan kriteria matang buah pada 6 TPH pada 3 collection road yang berbeda. Pengecekan mutu hancak 6 pemanen dengan fokus pengamatan buah tinggal dan brondolan tinggal.

5. Pengangkutan Tandan Buah Segar

Pengamatan cara pengumpulan dan pendataan jumlah TBS yang dapat diangkut pada hari pemanenan. Pencatatan waktu muat, waktu kirim ke PKS, waktu antri PKS, waktu bongkar loading ramp dan waktu kembali ke kebun.

Hasil pengamatan dibagi kedalam kelompok data primer dan data skunder. Analisis data menggunakan analisis deskripsi berdasarkan penentuan nilai rata - rata dan presentase yang menjadi ukuran perbandingan dari setiap aspek pengamatan. Analisis kuantitasif dilakukan berdasarkan pada data hasil pengamatan menggunakan uji $\mathrm{t} \quad-$ student maupun penghitungan nilai simpangan baku.

\section{KEADAAN UMUM LOKASI}

Kondisi iklim di Kebun Serawak Damai menurut pengamatan data curah hujan selama lima tahun terakhir, termasuk dalam tipe iklim A yaitu daerah sangat basah dengan rata - rata curah hujan tahunan adalah $3187.39 \mathrm{~mm}$ tahun $^{-1}$ berdasarkan klasifikasi Schmidt-Ferguson. Jenis tanah yang terdapat pada areal Kebun Serawak Damai terdiri dari inceptisol, entisol dan ultisol.

Luas areal Kebun Serawak Damai berdasarkan data 2014 adalah 3866 ha yang terdiri dari tanaman menghasilkan (TM) seluas 3 765.2 ha, areal tanaman belum menghasilkan (TBM) 2 sampai 4 seluas 100.8 ha dan seluruh areal tersebut merupakan kebun inti. Kebun Serawak damai dibagi menjadi 5 divisi, yaitu Divisi I dengan luas 854 ha yang terdiri dari blok 24 blok, Divisi II dengan luas 843 ha yang terdiri dari 23 blok, Divisi III dengan luas 855 ha yang terdiri dari 28 blok, Divisi IV dengan luas 633 ha yang terdiri dari 18 blok, Divisi V dengan luas 638 ha yang terdiri dari 17 blok.

\section{HASIL DAN PEMBAHASAN}

\section{Angka Kerapatan Panen (AKP) dan Taksasi Produksi}

Kegiatan memprediksi produksi dilakukan dengan menggunakan angka kerapatan panen sebagai perhitungan taksasi produksi. Kesesuaian taksasi produksi dengan realisasi produksi sangat bergantung pada keakuratan pengamatan AKP yang menjadi acuan penentuan kebutuhan tenaga kerja. Pengamatan dilakukan pada siang hari pada setiap blok yang akan dipanen pada esok hari. Pengambilan pokok contoh dilakukan secara acak dengan memilih setidaknya tiga jalur pasar pikul yang berbeda dalam satu blok. Jumlah pokok yang diambil sebanyak 300 pokok dengan hanya menghitung jumlah buah matang (2 brondolan hingga $75 \%$ brondolan permukaan telah terlepas).

Tabel 1. Hasil pengamatan AKP estimasi, AKP realisasi, taksasi produksi dan realisasi produksi

\begin{tabular}{lccccccccc}
\hline $\begin{array}{c}\text { Blok } \\
\text { panen }\end{array}$ & $\begin{array}{c}\text { Luas } \\
\text { areal } \\
\text { TM (ha) }\end{array}$ & $\begin{array}{c}\text { Berat } \\
\text { janjang } \\
\text { rata-rata } \\
(\mathrm{kg})\end{array}$ & SPH & $\begin{array}{c}\text { Jumlah } \\
\text { pokok } \\
\text { contoh }\end{array}$ & $\begin{array}{c}\text { Jumlah } \\
\text { buah } \\
\text { matang }\end{array}$ & $\begin{array}{c}\text { AKP } \\
\text { estimasi } \\
(\%)\end{array}$ & $\begin{array}{c}\text { AKP } \\
\text { realisasi } \\
(\%)\end{array}$ & $\begin{array}{c}\text { Taksasi } \\
\text { produksi } \\
(\mathrm{kg})\end{array}$ & $\begin{array}{c}\text { Realisasi } \\
\text { produksi } \\
(\mathrm{kg})\end{array}$ \\
\hline A38 & 34.39 & 8.2 & 145 & 300 & 105 & 35.00 & 36.00 & 14311 & 14720 \\
A39 & 22.65 & 8.8 & 140 & 300 & 95 & 31.67 & 38.88 & 8836 & 10850 \\
A40 & 31.56 & 7.2 & 136 & 300 & 93 & 31.00 & 35.13 & 9580 & 10856 \\
A41 & 32.19 & 8.4 & 139 & 300 & 88 & 29.33 & 31.24 & 11024 & 11741 \\
\hline
\end{tabular}




\begin{tabular}{|c|c|c|c|c|c|c|}
\hline Rata - rata & 140 & 300 & 31.75 & $35.31^{\mathrm{tn}}$ & 10938 & $12041^{\text {tn }}$ \\
\hline
\end{tabular}

- Contoh perhitungan Angka Kerapatan Panen (AKP) pada blok A38

$\mathrm{AKP}=\stackrel{\text { Jumlah buah matang pokok contoh }}{\text { Jumlah pokok contoh yang diamati }} \times 100 \% \Rightarrow \frac{105}{300} \times 100 \%=35.00 \%$

Contoh perhitungan taksasi produksi pada blok A38

Taksasi produksi $=\%$ AKP $\times$ Jumlah pokok ha ${ }^{-1} \times$ Total luas (ha) $\mathrm{x} \mathrm{BJR}(\mathrm{kg})$

Taksasi produksi $=35.00 \% \times 145 \times 34.39 \times 8.2 \mathrm{~kg}$

Taksasi produksi $=14311 \mathrm{~kg}$

Berdasarkan hasil pengamatan (Tabel 1) menunjukan bahwa nilai hasil AKP estimasi dan taksasi produksi tidak sama dengan nilai AKP realisasi dan produksi realisasi pada setiap blok. Perbedaan tersebut dipengaruhi oleh umur tanaman, stand per hektar (SPH), berat janjang rata - rata (BJR), luasan areal blok dan ketelitian dalam pengamatan. Taksasi produksi didapatkan melalui hasil perkalian persentase AKP, SPH, total luasan blok dan BJR. Nilai produksi realisasi yang selalu lebih tinggi dari pada nilai taksasi produksi mengakibatkan nilai AKP realisasi pasti akan selalu lebih tinggi dari nilai AKP estimasi pada perhitungan tersebut. Hal ini menunjukkan kurangnya ketelitian saat pengamatan AKP yang digunakan untuk mengetahui nilai taksasi produksi. Walaupun demikian, berdasarkan analisis uji $\mathrm{t}$ - student pada taraf nyata 5\% menunjukkan bahwa nilai AKP etimasi tidak berbeda nyata dengan AKP realisasi dan nilai taksasi produksi juga tidak berbeda nyata dengan nilai produksi realisasi. Persentase yang berbeda antara nilai AKP realisasi dan AKP estimasi dalam kasus ini dapat terjadi akibat turun hujan setelah pengamatan AKP estimasi. Hujan yang cukup lebat dapat merubah jumlah buah matang menjadi lebih banyak ditandai dengan bertambahnya brondolan jatuh. Maka pengamatan sebaiknya dilakukan pada waktu siang hingga sore hari setelah hujan reda.

\section{Tenaga Kerja Panen}

Keadaan umur tanaman mayoritas Divisi III SDME masih memiliki umur produksi yang cukup panjang. Maka dibutuhkan konsistensi kecukupan tenaga pemanen yang sesuai dengan potensi produksi tanaman agar dapat mencapai produktivitas optimum. Kegiatan pengelolaan pemanenan kelapa sawit bergantung pada keberhasilan pengelolaan tenaga kerja yang dipengaruhi oleh kemampuan keterampilan karyawan (Trismiaty et al., 2008). Pengamatan dilakukan pada kemampuan karyawan panen dalam menyelesaikan hancak yang diberikan. Pengamatan kemampuan karyawan panen dengan menghitung luasan yang dapat diselesaikan dalam 1 HK ( 7 jam kerja).

Kemampuan rata - rata 1 HK karyawan Divisi III SDME dapat menyelesaikan 2.8 hektar per hari. Nilai tersebut lebih kecil jika dibandingkan dengan nilai prestasi kerja yang biasa dipakai untuk menentukan jumlah kebutuhan tenaga panen pada Divisi III SDME yaitu 3 ha $\mathrm{HK}^{-1}$ (Tabel 2).

Tabel 2. Perubahan kebutuhan pemanen

\begin{tabular}{lcccc}
\hline Divisi & $\begin{array}{c}\text { Luas } \\
\text { (ha) }\end{array}$ & $\begin{array}{c}\text { Prestasi } \\
\text { kerja panen } \\
\left(\text { ha HK } \text { HK }^{-1}\right)\end{array}$ & $\begin{array}{c}\text { Seksi } \\
\text { panen }\end{array}$ & $\begin{array}{c}\text { Kebutuhan } \\
\text { TK panen }\end{array}$ \\
\hline 3 & 797.24 & 3 & 6 & 44 \\
3 & 797.24 & 2.8 & 6 & 47 \\
\hline
\end{tabular}

Berdasarkan perhitungan kebutuhan kerja berdasarkan norma panen buah menggunakan rumus :

Tenaga Kerja $=\frac{\text { Laas areal TM (lia) }}{\text { Tolial selks panten } \times \text { Prestisi keria (tha/IIK) }}$

Maka akan terjadi perubahan kebutuhan tenaga kerja yang harus dipenuhi dalam pemanenan suatu areal seksi panen. Kebutuhan tenaga kerja panen sebelumnya adalah 44 orang akan berubah menjadi 47 orang berdasarkan kemampuan panen rata - rata seperti yang disajikan pada Tabel 3. Saat ini Divisi III hanya memiliki 45 orang karyawan panen aktif yang dapat dipekerjakan. Penambahan sebanyak 2 orang diperlukan untuk mencukupi kebutuhan tenaga kerja panen. Kesesuaian jumlah tenaga kerja panen dengan jumlah kebutuhan panen akan meningkatkan kapasitas produksi pada kebun yang memiliki angka kerapatan panen baik. Seluruh potensi buah matang yang dihasilkan dapat dipanen dengan lebih maksimal dengan 
risiko keterlambatan minimal pada pusingan panen.

\section{Kriteria Panen dan Kualitas Panen}

Kriteria panen adalah kenampakan ciriciri pada buah sebagai pedoman kematangan dalam kegiatan pemanenan. SDME menerapkan kematangan berdasarkan jumlah brondolan yang telah terlepas dari tandan sebagai kriteria kematangan. Buah digolongkan sebagai buah matang apabila terdapat lebih dari lima brondolan yang jatuh secara alami disekitar piringan pokok (membrondol). Buah yang belum membrondol dikategorikan sebagai buah mentah. Buah yang sudah membrondol lebih dari $75 \%$ hingga $90 \%$ digolongkan ke dalam buah yang terlalu matang (over ripe). Kriteria kematangan buah secara lengkap dapat dilihat pada Tabel 4.

Tabel 3. Pengamatan kemampuan $1 \mathrm{HK}$ pemanen

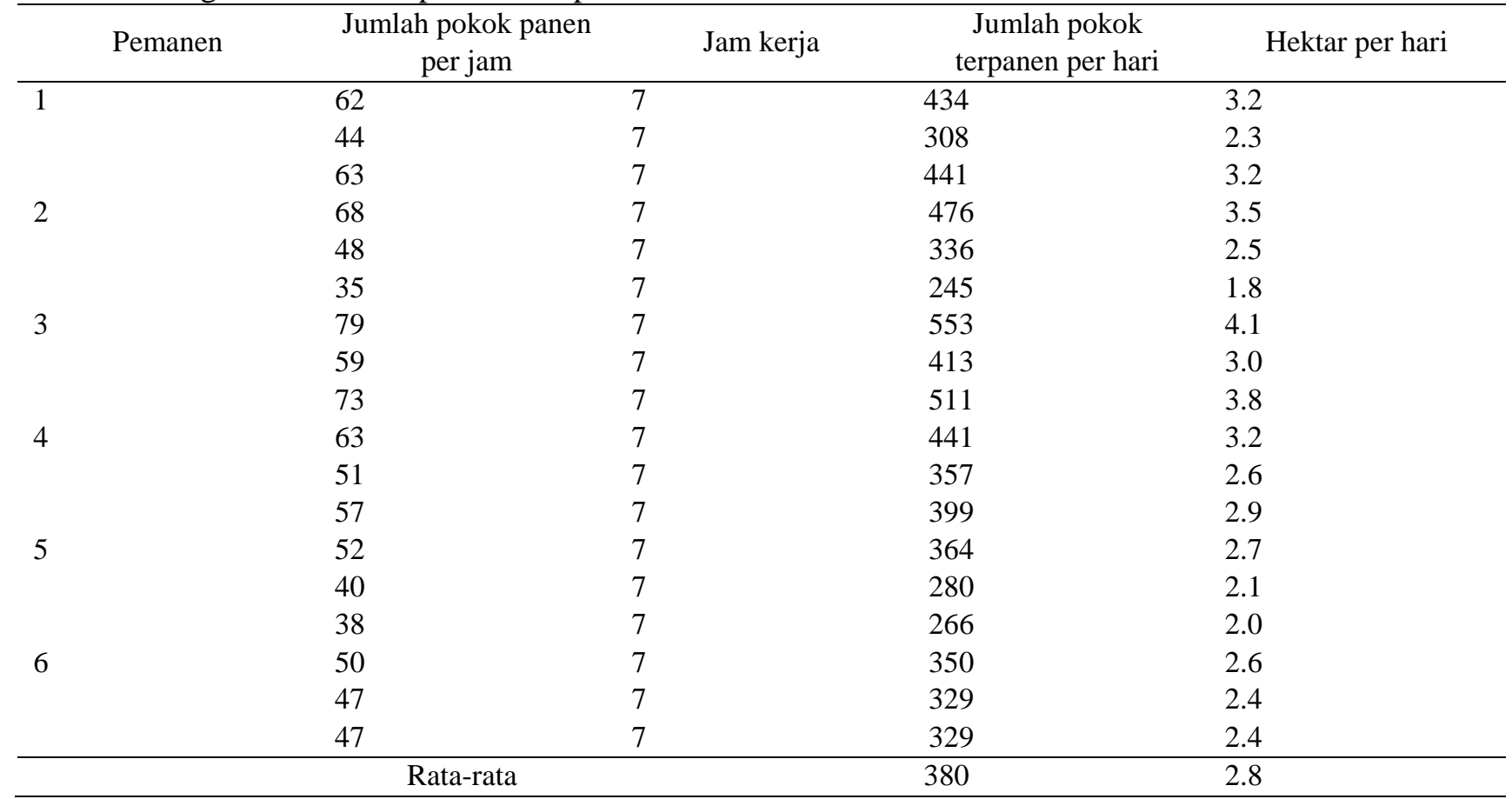

Tabel 4. Kriteria Grading berdasarkan tingkat kematangan buah (jumlah atau presentase brondolan)

\begin{tabular}{rlc}
\hline No & \multicolumn{1}{c}{ Kriteria } & TPH \\
\hline 1 & Mentah (Unripe) & 0 brondolan \\
2 & Kurang matang (Under ripe) & $<2$ brondolan $\mathrm{kg}^{-1}$ \\
3 & Matang (Ripe) & 2 brondolan hingga $75 \%$ brondolan permukaan telah lepas \\
4 & Terlalu matang (Over ripe) & $>75 \%-90 \%$ brondolan telah lepas \\
5 & Busuk / janjang kosong (Empty bunch) & $>90 \%$ brondolan telah lepas \\
\hline
\end{tabular}

Pengawasan pemanenan dilakukan pada seluruh kegiatan panen terdiri dari pemotongan buah di pokok, pemotongan tangkai buah di piringan, pengutipan brondolan, pengumpulan janjang dan brondolan di tempat pengumpulan hasil (TPH), penyusunan janjang panen dan pemberian tanda seluruh janjang hasil panen.

Pengawasan utama dilakukan pada mutu hancak dan mutu kematangan buah pada TPH. Pengecekan mutu hancak berupa rekapan data tentang jumlah pokok terpanen, jumlah buah tinggal, jumlah brondolan tinggal, jumlah buah tinggal per hektar dan jumlah brondolan tinggal per hektar. Jumlah harapan buah tinggal dalam 1 hektar adalah kurang dari $25 \%$ bobot hasil panen sedangkan jumlah harapan brondolan tinggal adalah kurang dari 30 butir per hektar. Berdasarkan hasil pengamatan pada Tabel 5 terdapat sebanyak 0.5 buah tinggal per hektar dan brondolan tinggal sebanyak 20.83 butir brondolan tinggal per hektar dari 6 orang pemanen yang diamati. Brondolan tinggal dan buah tinggal dalam pengamatan tersebut sudah memenuhi kriteria mutu yang diharapkan.

Mutu kematangan buah dilakukan pengawasan pada TBS hasil panen yang telah 
dikumpulkan di TPH. Mutu kematangan buah yang diharapkan adalah buah matang (ripe) lebih dari $85 \%$. Pengamatan mutu buah pada tiga collection road yang berbeda masing - masing mengambil 6 TPH secara acak. Hasil pengamatan mutu kematangan disajikan pada Tabel 6 dengan hasil persentase kematangan ripe sebesar $88 \%$.

Tabel 5. Hasil cek mutu hancak

\begin{tabular}{|c|c|c|c|c|c|c|}
\hline Pemanen & Pokok terpanen & Buah tinggal & Brondolan tinggal & $\begin{array}{c}\text { Jumlah pokok } \\
\text { sampel }\end{array}$ & $\begin{array}{c}\text { Buah tinggal } \\
\text { per ha }\end{array}$ & $\begin{array}{l}\text { Brondolan } \\
\text { tinggal per ha }\end{array}$ \\
\hline 1 & 53 & 0 & 10 & 152 & 0 & 9 \\
\hline 2 & 48 & 3 & 26 & 136 & 3 & 26 \\
\hline 3 & 53 & 0 & 7 & 152 & 0 & 6 \\
\hline 4 & 49 & 0 & 23 & 140 & 0 & 22 \\
\hline 5 & 54 & 0 & 50 & 154 & 0 & 44 \\
\hline 6 & 47 & 0 & 17 & 134 & 0 & 17 \\
\hline \multicolumn{2}{|c|}{ Rata - rata } & 0.50 & 22.17 & 144.67 & 0.50 & 20.83 \\
\hline
\end{tabular}

Tabel 6. Mutu kematangan TBS di TPH Divisi III Serawak Damai Estate Maret - Juni 2014

\begin{tabular}{|c|c|c|c|c|c|c|}
\hline Collection road & $\mathrm{TPH}$ & Unripe & Under ripe & Ripe & Over rive & Empty bunch \\
\hline \multirow[t]{6}{*}{ A42/43 } & 1 & 0 & 1 & 20 & 3 & 0 \\
\hline & 2 & 0 & 0 & 19 & 1 & 0 \\
\hline & 3 & 0 & 0 & 18 & 0 & 0 \\
\hline & 4 & 0 & 2 & 35 & 1 & 0 \\
\hline & 5 & 0 & 2 & 21 & 4 & 1 \\
\hline & 6 & 0 & 0 & 25 & 0 & 0 \\
\hline \multicolumn{2}{|l|}{ Subtotal } & 0 & 5 & 138 & 9 & 1 \\
\hline \multirow{6}{*}{$\mathrm{B} 45 / 46$} & 1 & 0 & 0 & 23 & 0 & 1 \\
\hline & 2 & 0 & 1 & 32 & 1 & 0 \\
\hline & 3 & 0 & 1 & 27 & 2 & 2 \\
\hline & 4 & 0 & 4 & 16 & 0 & 0 \\
\hline & 5 & 0 & 1 & 17 & 3 & 1 \\
\hline & 6 & 0 & 0 & 35 & 0 & 3 \\
\hline \multicolumn{2}{|l|}{ Subtotal } & 0 & 7 & 150 & 6 & 7 \\
\hline \multirow[t]{6}{*}{ C40/41 } & 1 & 0 & 1 & 26 & 5 & 2 \\
\hline & 2 & 0 & 0 & 40 & 2 & 1 \\
\hline & 3 & 0 & 0 & 33 & 0 & 3 \\
\hline & 4 & 0 & 1 & 29 & 1 & 0 \\
\hline & 5 & 0 & 0 & 33 & 5 & 3 \\
\hline & 6 & 0 & 3 & 24 & 0 & 0 \\
\hline Subtotal & & 0 & 5 & 185 & 13 & 9 \\
\hline Total & & 0 & 17 & 473 & 28 & 17 \\
\hline Persentase & & - & $3 \%$ & $88 \%$ & $5 \%$ & $3 \%$ \\
\hline
\end{tabular}

\section{Transportasi Buah}

Kegiatan ini bermula dengan dibaginya karyawan bongkar muat (BM) menjadi kelompok terdiri dari tiga orang. Tim BM bekerja secara terus-menerus mengikuti setiap alur pengiriman yang dilakukan oleh satu truk atau bergantian apabila ketersediaan angkutan buah tidak maksimal. Pengecekan terlebih dahulu dilakukan oleh krani panen terhadap buah yang telah dibawa keluar oleh pemanen. Hasil pengecekan tersebut digunakan krani panen untuk menentukan buah
Jika dibandingkan dengan standar yang diterapkan maka persentase kematangan ripe sudah mencukupi, sedangkan standar kematangan empty bunch masih terlalu tinggi dengan hasil pengamatan sebesar $3 \%$. 
mungkin ke pabrik untuk diproses. Terkadang terjadi keterlambatan pengiriman buah yang mengakibatkan proses muat harus dilakukan pada malam hari. Tidak jarang karena keterlambatan pengangkutan buah terjadi buah restan dilapangan. Buah restan adalah buah hasil panen hari ini yang belum dapat dikirim pada hari ini akibat berbagai sebab keterlambatan kirim. Muat buah yang dilakukan malam hari juga mengakibatkan kehilangan hasil (losses) brondolan yang tinggi di TPH. Divisi harus memberikan biaya ekstra untuk membersihkan dan mengumpulkan losses yang terjadi. Penyebab keterlambatan pengiriman buah yang mengakibatkan sering tejadi muat malam belum dapat diketahui, maka penulis melakukan pengamatan terhadap konsistensi pada proses pengiriman buah.

Pengamatan transportasi buah dilakukan dengan mengamati variasi waktu muat, waktu ke PKS, waktu antri PKS, waktu bongkar loading ramp dan waktu kembali ke kebun. Setiap jenis waktu dilakukan pengulangan sebanyak 9 kali yang merupakan rangkaian satu siklus pengiriman buah. Pengamatan waktu tersebut digunakan untuk membandingkan dua tujuan pengiriman yaitu Selucing Agro Mill (SAGM) dan Pundu Nabatindo Mill (PNBM). Kedua data hasil pengamatan tersebut disajikan pada lima grafik dibawa ini.

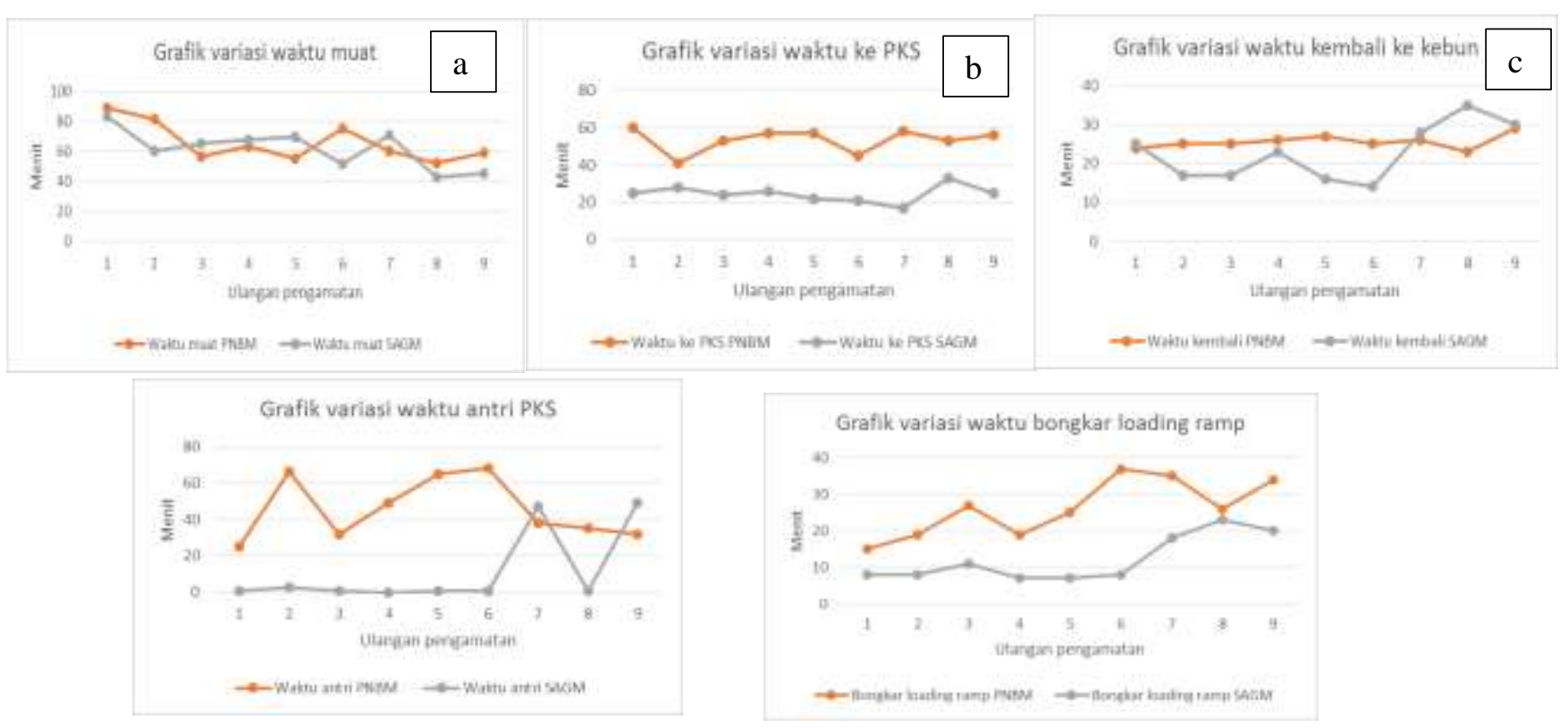

Gambar 1. a. Grafik variasi waktu muat; 4 d ffik variasi waktu ke PKS; c. Grafik varias e tu kembali ke kebun; d. Grafik variasi waktu crrm PKS; e. Grafik variasi waktu bongkar loadin_ e rump.

Kemudian dari data tersebut ditentukan nilai ektrim atas, nilai ekstrim bawah, rata - rata (mean) dan simpangan baku contoh (S) pada setiap jenis waktu yang diamati (Tabel 7).
Analisis statistik dengan menentukan simpangan baku contoh dilakukan dengan menggunakana rumus :

$$
s^{2}=\frac{n{ }_{i=1}^{n} x_{i}^{2}+\left(\prod_{i=1}^{n} x i\right)}{n}
$$

Tabel 7. Hasil analisis simpangan baku contoh

\begin{tabular}{lcccccccc}
\hline \multirow{2}{*}{ Pengamatan } & \multicolumn{2}{c}{ Simpangan baku } & \multicolumn{2}{c}{ Nilai ekstrim atas } & \multicolumn{2}{c}{ Nilai ekstrim bawah } & Mean \\
\cline { 2 - 8 } & PNBM & SAGM & PNBM & SAGM & PNBM & SAGM & PNBM & SAGM \\
\hline Waktu muat (menit) & 12.96 & 13.35 & 89 & 83 & 52 & 42 & 65 & 61 \\
Waktu ke PKS (menit) & 6.34 & 4.50 & 60 & 33 & 41 & 17 & 53 & 24 \\
Waktu antri (menit) & 16.85 & 20.68 & 68 & 49 & 25 & 0 & 45 & 11 \\
Waktu bongkar (menit) & 7.79 & 6.32 & 37 & 23 & 15 & 7 & 26 & 12 \\
Waktu kembali (menit) & 1.74 & 7.28 & 29 & 35 & 23 & 14 & 25 & 22 \\
\hline
\end{tabular}


Nilai simpangan baku contoh pada setiap jenis waktu pengamatan yang dapat memberikan informasi terhadap keberagaman variasi data masing - masing. Simpangan baku contoh merupakan ukuran keberagaman terbaik yang dimiliki suatu data dengan syarat memiliki satuan pengukuran yang sama dan nilai tengah yang hampir sama. Semakin besar nilai simpangan baku contoh suatu data maka semakin besar pula keragamannya dan sebaliknya. Secara berurutan nilai simpangan baku contoh dari yang tertinggi adalah waktu antri PKS dan waktu muat. Maka dapat diperkirakan bahwa pada proses muat dan antri PKS akan lebih sering menyebabkan variasi waktu yang beragam menimbulkan kemungkinan terjadi keterlambatan lebih besar dibanding dengan jenis waktu lain dalam proses transportasi buah. Diperlukan perbaikan dalam kendala teknis dan koordinasi yang terkait proses tersebut untuk meningkatkan optimalisasi fungsi transportasi buah (Tabel 7).

\section{Produksi}

Produksi hasil panen TBS yang dihasilkan dari seluruh proses budidaya kelapa sawit termasuk didalamnya keberlanjutan dalam pencapaian hasil panen optimum secara konsisten menjadi cermin keberhasilan manajemen produksi.

Tabel 8 menunjukkan bahwa hasil produksi realisasi terhadap budget produksi berbeda. Keadaan tersebut menunjukkan bahwa kebun Divisi III memiliki potensi produksi yang melebihi perkiraan. Hal tersebut dapat terjadi akibat pengaruh banyak faktor budidaya maupun lingkungan.

Tabel 8. Pencapaian produksi Divisi III SDME

\begin{tabular}{ccccc}
\hline Bulan & $\begin{array}{c}\text { Budget produksi } \\
(\mathrm{kg})\end{array}$ & $\begin{array}{c}\text { Realisasi } \\
\text { produksi }(\mathrm{kg})\end{array}$ & $\begin{array}{c}\text { Pencapaian } \\
\text { produksi }(\%)\end{array}$ & Selisih $(\mathrm{kg})$ \\
\hline Maret & 1348536 & 1665230 & 123 & 316694 \\
April & 1406330 & 1708210 & 121 & 301880 \\
Mei & 1425595 & 1939404 & 136 & 513809 \\
Juni & 1175153 & 1875880 & 156 & 700727 \\
Juli & 1560449 & 1552637 & 99 & -7812 \\
\hline Rata-rata & 1383212 & $1748272 *$ & 128 & 365059 \\
\hline Sumber : Kantor Kebun Serawak Damai; Keterangan : * beda nyata pada taraf 5\% &
\end{tabular}

\section{KESIMPULAN}

Kegiatan manajemen pemanenan kelapa sawit pada Divisi III Kebun Serawak Damai menerapkan sistem pemanenan yang cukup efektif. Pelaksanaan kegiatan panen mencakup penentuan rotasi panen, nilai AKP harian, taksasi panen harian, kebutuhan tenaga panen, pemotongan tandan buah segar, pengiriman buah ke PKS dan pengawasan. Kegiatan pemotongan buah memiliki hasil yang cukup baik berdasarkan standar perusahaan. Nilai AKP etimasi tidak berbeda dengan AKP realisasi, sedangkan nilai taksasi produksi tidak berbeda dengan nilai realisasi produksi. Kemampuan panen karyawan hasil pengamatan dilapangan rata - rata sebesar 2.8 ha $\mathrm{HK}^{-1}$. Mutu kematangan bauh ripe mencapai $88 \%$ sesuai dengan harapan, sedangkan empty bunch masih terdapat 3\% dari keseluruhan hasil panen. Pengawasan dengan melakukan pendampingan langsung kepada karyawan saat kegiatan panen berlangsung, pembuatan laporan mutu buah di tempat pengumpulan hasil, laporan mutu hancak dan laporan harian mandor. Pengiriman buah masih dirasa kurang karena sering terjadi keterlambatan transportasi bauh dan terjadi buah restan. Keterlambatan transportasi buah ditandai dengan variasi waktu yang dibutuhkan unit transportasi buah akibat tidak lancarnya proses antri PKS dan muat buah.

\section{DAFTAR PUSTAKA}

Akbar, A. 2008. Manajemen panen di perkebunan kelapa sawit (Elaeis guineensis Jacq.) di Pantai Butani Estate PT Sajang Heulang Minamas Plantation Tanah Bambu Kalimantan Selatan [skripsi]. Bogor (ID): Institut Pertanian Bogor.

Fauzi, Widyastuti, Satyawibawa, Paeru. 2012. Kelapa Sawit Budidaya Pemanfaatan Hasil dan Limbah Analisis Usaha dan Pemasaran. Jakarta (ID): Penebar Swadaya.

Dirjenbun. 2012. Produksi, Luas Areal dan Produktivitas Perkebunan di Indonesia [internet]. [diunduh 2015 Sep 29]. Tersedia pada 
www.deptan.go.id/Indikator/tabel-3-prodlsarel-prodvitas-bun.pdf

Gomes, K A, Gomes, AA. 2007. Prosedur Statistik untuk Penelitian Pertanian. Jakarta (ID): Penerbit Universitas Indonesia.

Hutagaol, H. 2009. Manajemen panen tanaman kelapa sawit (Elaeis guineensis Jacq.) di Sungai Pinang Estate PT Bina Sains Cemerlang Minamas Plantation Musi Rawas Sumatera Selatan [skripsi]. Bogor (ID): Institut Pertanian Bogor.

Lubis, AU. 1992. Kelapa sawit (Elaeis guineensis Jacq.) di Indonesia. Medan (ID): Pusat Penelitian Perkebunan Marihat.

Lubis, RE, Widanarko A. 2012. Buku Pintar Kelapa Sawit. Jakarta (ID): Agromedia Pustaka

Mangoensoekarjo, Semangun, H. 2003. Manajemen Agrobisnis Kelapa Sawit. Yogjakata (ID): Gadjah Mada University Press.

Miranda, R.R. 2009. Manajemen panen tanaman kelapa sawit (Elaeis guineensis Jacq.) di PT Gunung Keemasan Estate Minamas Plantation Pulau laut Kalimantan Selatan [skripsi]. Bogor (ID): Institut Pertanian Bogor.
Nu'man, M. 2009. Pengelolaan tenaga kerja perkebunan kelapa sawit (Elaeis guineensis Jacq.) di perkebunan PT Cipta Futura Plantation Muara Enim Sumatera Selatan [skripsi]. Bogor (ID): Institut Pertanian Bogor.

Pahan, I. 2010. Panduan Lengkap Kelapa Sawit: Manajemen Agribisnis dari Hulu Hingga Hilir. Jakarta (ID): Penebar Swadaya, anggota Ikapi.

[PPKS] Pusat Penelitian Kelapa Sawit. 2007. Budidaya Kelapa Sawit. Medan (ID): Pusat Penelitian Perkebunan Marihat.

Risza, S. 2010. Masa Depan Perkebunan Kelapa Sawit Indonesia. Yogyakarta (ID): Kanisius (Anggota IKAPI).

Setyamidjaja, D. 2006. Kelapa Sawit Teknik Budidaya, Panen dan Pengolahan. Yogyakarta (ID): Kanisius (Anggota IKAPI).

Trismiaty, Listiyani, Mubaraq, T.Z. 2008. Manajemen tenaga kerja panen kelapa sawit di PT Perkebunan III (Persero) Kebun Aek Nabara Selatan Labuhan Batu Sumatera Utara. Buletin Ilmiah Instiper. 15

(1):

15-23. 